\title{
A Judicialização das Relações Familiares: uma Análise do Fenômeno na Perspectiva da Sociedade de RIsCO
}

\author{
Aloísio RusCHEINSKY ${ }^{1}$ \\ Melissa DeMARI ${ }^{2}$
}

\begin{abstract}
Resumo
Na contemporaneidade, a previsibilidade e a segurança das relações sociais, enquanto valores consagrados e sedimentados pela modernidade, cederam lugar à insegurança e inerentes riscos das mudanças. A insegurança, como fenômeno contemporâneo, produzido pelo avanço tecnológico, irradia os seus efeitos em todas as dimensões da vida humana, notadamente nas dimensões física, psicológica e social. Esse processo está no alicerce da percepção dos riscos como eixo-social fundamental da análise das ciências sociais. Nessa perspectiva, a forma de o indivíduo pensar e constituir a si próprio criou inúmeros avanços e possibilidades para a reconfiguração das instituições sociais. Não obstante, na vida cotidiana, com suas relações formais e informais, e com a publicização da intimidade, os indivíduos se digladiam entre a segurança do passado e as possibilidades do futuro.
\end{abstract}

Palavras-chave: Risco. Judicialização. Relacionamentos. Conflitos.

1 Doutor em Sociologia pela Universidade de São Paulo. Professor do Programa de Pós-Graduação em Ciências Sociais da Universidade do Vale do Rio dos Sinos (UNISINOS), Brasil. aloisior@unisinos.br

2 Doutoranda em Ciências Sociais e mestre em Direito Público pela Universidade do Vale do Rio dos Sinos (UNISINOS). Professora dos Cursos de Graduação e Pós-Graduação em Direito da Universidade de Caxias do Sul - UCS, Brasil. melissademari@terra.com.br 


\title{
The Legalization of the Relations in the Family: an Analysis of the Phenomenon Considering the Perspective of Risk SOCIETY
}

\begin{abstract}
In contemporary times, the predictability and security of social relations, as established and verified by modern values, gave way to uncertainty and the inherent risks of change. Insecurity, while a contemporary phenomenon produced by technological advance, radiates its effects to all dimensions of human life, notably the physical, psychological and social. This process is the pinnacle of risk perception and forms the fundamental axis of the social sciences' analysis. The way an individual thinks and forms himself gave way to numerous advances and possibilities for the reconfiguration of social institutions. Notwithstanding, with the formal and informal relationships of everyday life and the publicization of intimacy, individuals battle between the security of the past and the possibilities of the future.
\end{abstract}

Keywords: Risk. Judicialization. Relationships. Conflicts.

\section{INTRODUÇÃo}

A modernidade, como um período histórico-social, produziu possibilidades científicas e teorias de interpretação que permitem compreender a sociedade a partir de critérios racionais, consolidando, assim, valores e categoriais sociais, calcados na segurança e na previsibilidade. Todavia, com os avanços tecnológicos, experimentados ao longo das últimas décadas, a segurança e as respostas ante o desconhecido cederam lugar à incerteza e ao risco, produzidos por este fenômeno. Torna-se, portanto, relevante analisar de que forma os indivíduos na sociedade contemporânea vêm se relacionando com os riscos e as incertezas, como uma nova realidade, inserida no processo de individualização.

O presente texto examinará, desta forma, as implicações da noção e da percepção dos riscos na vida humana, notadamente para as dimensões física, psicológica e social. O estudo pretende igualmente examinar a ambiguidade em curso no que se refere aos processos 
de informalização de relações interpessoais e, ao mesmo tempo, ao recurso institucional para a resolução de conflitos que denominamos "judicialização". Esse fenômeno creditamos ao percurso ou aos desdobramentos do que chamamos de "sociedade de risco".

Como teóricos que refletem sobre o referido fenômeno na sociedade contemporânea, Ulrich Beck (2010) e Antony Giddens (1997) explicam por que a atualidade está distante dos primórdios da modernidade. Os autores apontam que, nas últimas décadas, o conceito de risco passou a ser central na teoria social, contribuindo para uma mudança de perspectiva na análise das relações sociais e propondo que o conceito de sociedade do risco vem se destacando em detrimento da noção de sociedade de classes e, por vezes, sendo substitutivo na tentativa de apropriação da realidade pela teoria social. Os riscos, de maneira geral, escapam à imediata percepção humana, mas possuem efeitos de curto e longo prazo, e, cedo ou tarde, acabam alcançando, de alguma forma, a todos. Todavia, os riscos são decorrentes do sucesso da modernidade e menos, de uma crise, ao mesmo tempo em que são uma construção social inerente ao progresso.

\section{A Centralidade do risco na Contemporaneidade \\ E REFLEXIVIDADE}

A centralidade do risco, na compreensão da sociedade contemporânea, refere-se a uma associação entre o avanço tecnológico e a paulatina compreensão da ambiguidade dos efeitos da tecnologia sobre a sociedade. De forma similar, a instabilidade das relações familiares e a percepção de riscos ou perdas, sofridas em decorrência de outras pessoas, fazem crescer o apelo para a resolução jurídica dos conflitos.

A partir dessa reflexão, aponta-se para a centralidade da noção de risco como um novo paradigma, que traz consequências para 
a gestão das relações sociais na contemporaneidade. Nesse sentido, o processo de modernização social concorre, de forma veemente, para um aumento significativo de riscos sociais, ambientais, tecnológicos e simbólicos, assim como para as suas múltiplas manifestações de incertezas, por vezes, invisíveis, imperceptíveis, imprevisíveis, em sintonia com frágeis instrumentos de controle. Muda, então, o campo dos conflitos, como um deslocamento, segundo registra Beck:

[...] na modernidade tardia, a produção social de riquezas é acompanhada sistematicamente pela produção social de riscos. Consequentemente, aos problemas e conflitos distributivos da sociedade de escassez sobrepõemse os problemas e conflitos surgidos a partir da produção, definição e distribuição de riscos científicotecnologicamente produzidos (BECK, 2010, p. 23).

Os riscos incluem e combinam, ao mesmo tempo, ganhos e incertezas. Da mesma forma, têm sido alvo de críticas, como a que se refere à proposição da centralidade para a análise das ciências sociais. As contribuições, no entanto, não perdem a vitalidade e a legitimidade, principalmente, pela importância adquirida pelos riscos e incertezas na contemporaneidade. Ulrich Beck e Antony Giddens pontuam a centralidade do risco para a compreensão da sociedade contemporânea:

[...] o conceito de risco passou a ocupar um lugar central na teoria social. Dois dos mais importantes e influentes teóricos sociais contemporâneos, Ulrich Beck e Anthony Giddens, contribuíram, decisivamente, para isto, ao considerarem os riscos, em especial os ambientais e tecnológicos de graves conseqüências, como chaves para entender as características, os limites e transformações do projeto histórico da modernidade. Discutindo o caráter daqueles riscos, Beck e Giddens passaram a dar nova luz a questões referentes aos conflitos sociais, as relações entre leigos e peritos, ao papel da ciência e formas de fazer e definir a política (GUIVANT, 1998, p. 3). 
Tanto para Beck quanto para Giddens, a sociedade contemporânea - que vivencia a modernidade acentuada - caracteriza-se pela radicalização dos princípios que orientaram o processo de modernização. Isso demarcaria a passagem da sociedade moderna para a alta modernidade ou a reflexividade em que se encontra a modernidade reflexiva.

A sociedade de risco, tal qual referida e aqui apresentada, não está totalmente consolidada ou uniformizada (WESTPHAL, 2010), mas, sim, em processo de implementação, mesmo porque os processos de transformação social não correm de forma linear, simultânea e homogênea.

Vivemos em um regime social que, de forma gradual, cada vez mais se torna incapaz de servir como núcleo predominante de uma ordem social legítima. O resultado imediato advém dos níveis elevados e desconhecidos de incerteza, a partir dos quais a vida das pessoas parece cada vez mais governada pelo acaso e pelo engendramento de riscos que tendem a não ser tolerados do ponto de vista ético. Destaca-se, assim, que os avanços tecnológicos requerem uma subscrição de legitimidade.

O progresso, gerado pela evolução científica e tecnológica, passou a ser considerado uma fonte potencial de criação de novas performances e, simultaneamente, de autodestruição da sociedade, por meio do qual se produzem novos riscos de caráter global, que afetam os indivíduos em particular e o planeta, sem nítida distinção de classe ou nacionalidade. Tais riscos trazem consequências de alta gravidade, mas, em geral, desconhecidas por parte dos leigos, e que não podem ser avaliadas com precisão. Como exemplo das consequências dos ris$\cos _{\text {gerados }}{ }^{3}$ pela acentuação dos processos tecnológicos, podem ser

3 As contradições e os riscos em curso, diz o sociólogo Wolfgang Streeck, podem agravar as múltiplas faces das crises de destruição e devastação dos bens naturais, sem que algo novo esteja pronto para substituir. "Vamos ver que medidas virão a seguir, quando o dinheiro dos bancos centrais enfim tiver se tornado demasiado tóxico". (INSTITUTO HUMANITAS 
citadas mudanças climáticas, poluição dos recursos hídricos, contaminação alimentar, radioatividade, ecotoxicidades, entre outros aspectos.

A partir de acidentes ou incidentes de elevado impacto ambiental e considerando a realidade alemã, Beck pondera que a satisfação das necessidades materiais básicas teria sido substituída pela preocupação com os riscos, inclusive o potencial da autodestruição. Os fatos em torno da energia nuclear põem em pauta o envenenamento químico e a interrogação sobre a autonomia da sociedade em uma economia guiada pelo desenvolvimento científico-tecnológico. Os riscos, por consequência, perpassam classes e nações, portanto uma inovação a ser compreendida como construção social.

Algumas premissas amparam a análise social a partir dos riscos sob sua dimensão de invisíveis e imateriais, de modo que cumpre identificá-los e mobilizar-se politicamente, para contê-los. Quando são percebidos, eles já são reais, e a capacidade de respostas para a solução destes já foi prejudicada (BECK, 2010). Assinala-se também que as questões ambientais envolvem e requerem conhecimento técnico, para interpretar e compreender a amplitude dos riscos que representam. Na ótica de Giddens (1997), um momento de reflexividade parece um dos requisitos de informação para a mobilização dos cidadãos.

O autor faz considerações, segundo as quais, a manipulação tecnológica sobre o meio ambiente colocou a sociedade em uma encruzilhada, pois, em que pese os benefícios no tocante à expectativa e qualidade de vida decorrentes, este fenômeno acarretou e acarretará consequências para o meio ambiente e a vida cotidiana que sequer podem ser dimensionadas, em razão do seu potencial de risco. Somando-se a isso, temos um risco de implosão da regulação social no que diz respeito a dimensões cruciais: trabalho, bens naturais e moeda.

Como produto da modernidade reflexiva, os riscos também são autorreferenciais, e a busca pela sua contenção acaba gerando no-

UNISINOS, 2015). 
vos riscos, sejam eles tecnológicos, subjetivos ou sociais. Salienta-se ainda que, na contemporaneidade, a fase da modernidade reflexiva, pela sua própria dinâmica, constitui-se em novas formas de conflitos sociais e coalizões políticas (GUIVANT, 1998). A noção de modernidade reflexiva exibe-se fundamental para a compreensão da sociedade do risco, eis que aponta para uma configuração em que a riqueza se converteu na produção social de riscos, sobretudo sob o domínio científico-tecnológico

Tal apreciação traduz a emergência das considerações da sociedade sobre si mesma, ou ela tornou-se um problema para ela própria. As tramas sociais e os processos constituintes da modernidade atuam sobre ela própria, passando a ser, eles próprios, o fundamento e o objeto de sua própria crítica. Em vez de uma teoria crítica da sociedade, aparece uma teoria da autocrítica social para análise dos conflitos. "Numa sociedade que se autodefine como sociedade de risco a crítica se democratiza; quer isto dizer que se estabelecem mecanismos de crítica recíproca entre as racionalidades dos universos simbólicos da sociedade e os grupos que as constituem (BECK, 1996, p. 220). Desta forma, as perspectivas e os pressupostos que se abrem na direção de uma sociologia da sociedade de risco estão demarcadas pela noção de modernização reflexiva.

$\mathrm{Na}$ fase modernidade reflexiva, na qual se assenta a sociedade de risco, o movimento consumou o seu oposto, e a crítica volta-se a si própria, a partir de seus próprios fundamentos, tornando-se autorreferencial (BECK, 2010, p. 13). Neste direcionamento, a sociedade volta-se para si própria, e a revisão crítica produz destruição criativa de conceitos e instituições.

Giddens assume uma postura menos dramática, ao analisar a sociedade contemporânea, pois acredita que "viver no universo da alta modernidade é viver num ambiente de opções e riscos, concomitantemente, inevitáveis de um sistema orientado para o domínio da 
natureza e construção reflexiva da história" (GIDDENS, 1997, p. 109). Contudo, em sua exposição, reforça parcialmente a teoria de Beck, assumindo que os riscos da modernidade não são necessariamente maiores que os do passado, mas aqueles eram efeitos da natureza e podiam ser facilmente dimensionados. A seu turno os riscos atuais são, em grande parte, fruto da aplicação tecnológica com risco por vezes inevitável, portanto, produzidos artificialmente pela ação humana. Paradoxalmente aos riscos que produz, a sociedade atual está bastante preocupada com o futuro e a segurança. Ela produz risco, mas almeja segurança, e os indivíduos têm cada vez mais dúvidas sobre as consequências da produção tecnológica e os efeitos de sua ação sobre a natureza.

Neste sentido, os rumos dos desdobramentos científicos conduzem a um desencantamento, visto que a crença na certeza do conhecimento foi profundamente abalada e substituída pela convicção do possível potencial de dano. Contudo, existem desdobramentos que levam a mitigar alguns espaços potencialmente geradores de riscos. $\mathrm{O}$ desenvolvimento de políticas públicas pode ser importante, enquanto tentativa de mudança de paradigma e conscientização coletiva, cujo efeito desejado se expande dentro da lógica de gestão pública compartilhada. Para exemplificar, na questão da coleta seletiva, especialmente se assenta um grau de participação de cada indivíduo da coletividade para a ampliação do sucesso e a concepção de acolher os anseios sociais pela mitigação dos efeitos nefastos da ação humana sobre a natureza. Nesse caso, os indivíduos consolidam-se como a fonte do direito de mitigação dos efeitos perversos, seguindo a lógica de articulação e reflexividade que sucede o engajamento dos atores sociais.

Assim, o corpo se transforma no produto do espaço de opções e escolhas que o sujeito faz nas esferas do conhecimento que são capazes de afetá-lo (engenharia genética, reprodução biológica). Essas possibilidades de escolha sobre o projeto pessoal são contraditoriamen- 
te acompanhadas por um descrédito acerca do conhecimento perito, sempre sob revisão e debate.

\section{A transmutação das Relações Cotidianas Na SOCiedade de Risco}

O aumento na complexidade da vida contemporânea gerou reflexos em vários aspectos da vida pessoal dos indivíduos. Nesse cenário, o texto seguirá apresentando e contextualizando situações da vida cotidiana que operam em sintonia com a sociedade de risco e acabam acentuando o processo de judicialização, conforme será adiante analisado.

A sociedade industrial, de certo modo, consolidou o modelo de família nuclear. Enquanto a mulher realizava o trabalho doméstico, não remunerado, em prol do bem familiar, o homem exercia o trabalho remunerado. Sob a égide da industrialização, foram consolidadas duas épocas distintas, que Beck chama de "modernidade" e "antimodernidade", ambas baseadas em princípios e valores distintos, porém elas "complementam-se, condicionam-se e contradizem-se" (BECK, 2010, p. 164).

Essa distinção entre o trabalho doméstico e assalariado, que a sociedade moderna tradicionalmente atribuiu a homens e mulheres na família, abrange diferentes épocas, pois reflete o papel social e a visão de si, de cada um dos membros da unidade familiar. O trabalho externo, produtivo, torna o seu executor um provedor de si e de terceiros, alçando-o à condição de portador de processos de mobilidade; já o doméstico, a seu turno, torna o seu executor titular de um status de incapaz de prover o seu próprio sustento, tendo o casamento como condição de assim provê-lo. Esses papéis sociais, atribuídos a homens e mulheres, são imunes à escolha de cada um, e designados, em razão do sexo do indivíduo. 
Aquilo que lamentamos como as misérias da intimidade são, na verdade, os paradoxos de sociedade industrial (BECK, 2010), que teve as suas próprias e inerentes diferenças relativas aos sexos, em especial, nos séculos XIX e início do século XX.

Todavia, com o avanço do Estado do Bem-Estar Social, houve uma amenização na dissociação desses papéis sociais, historicamente atribuídos a homens e mulheres, na configuração familiar, na modernidade. As mulheres passaram a assumir postos de trabalho, e, com isto, houve uma reinterpretação, de acordo com Beck (2010, p. 165), da "moral familiar, dos seus destinos sexuais, de seus tabus relacionados ao casamento, à paternidade, à sexualidade, ocorrendo até mesmo a reunificação de trabalho profissional e doméstico".

Na obra Modernidade Líquida, Bauman (2001) lembra uma entrevista, concedida por Beck a Jonathan Rutherford, no ano de 1999. Ao falar sobre a sociedade moderna, que se volta sobre si própria, para colocar em suspenso, criticar e reelaborar os seus próprios conceitos e instituições, Beck pontua que a família se tornou uma 'instituição zumbi' (BAUMAN, 2001), que está morta, permanecendo ainda viva, visto que assume novos conteúdos e novos significados dentro da sua antiga denominação.

Pergunte-se o que é realmente uma família hoje em dia? O que significa? E claro que há crianças, meus filhos, nossos filhos. Mas, mesmo a paternidade e a maternidade, o núcleo da vida familiar, estão começando a se desintegrar no divórcio ... Avós e avôs são incluídos e excluídos sem meios de participar nas decisões de seus filhos e filhas. Do ponto de vista de seus netos, o significado das avós e dos avôs tem que ser determinado por decisões e escolhas individuais (BAUMAN, 2001, p. 13).

Associando-se ao seu interlocutor, Bauman completa que as instituições sociais tradicionais - como é o caso da família - foram constituídas e consolidadas há um longo tempo. A modernidade, em 
sua fase inicial, tratou de derreter ou desarticular essas instituições, criticando-as, e agora elas estão sendo reconstruídas. O autor aponta, contudo, que mesmo sem perceber, na modernidade, os indivíduos só abrigam-se em outras instituições, ainda que reformuladas. Ou seja: o que ocorreu ali foi uma das substituições de antigos por novos padrões, ainda que aperfeiçoados. Conforme apontado acima, a modernização reflexiva produz uma nova forma de a sociedade refletir sobre si própria.

No que interessa ao presente trabalho, Beck assevera que, se a família, em seu modelo nuclear, consolidou-se no início da fase moderna, a bem de possibilitar o desenvolvimento e o fortalecimento da industrialização, na acentuação da modernidade, com a destradicionalização da família, surgiram os conflitos desse modelo institucional. O autor aponta também que os confrontos de classe são fruto da forma de produção típica da modernidade. Os confrontos entre os sexos, a seu turno, não se enquadram nos esquemas dos confrontos de classe nem tampouco são resquícios de uma tradição. Eles são produto e fundamento do sistema industrial, pois, para que o trabalho industrial aconteça, é preciso que haja o trabalho doméstico, de forma que um é pressuposto de outro (BECK, 2010, p. 163-164). Juntamente com essa separação, a sociedade atribuiu papéis sociais a homens e mulheres, e, mais tarde, essa separação social de papéis acabou gerando conflitos no âmbito familiar.

Na sociedade de risco ou alta modernidade, as formas institucionais passaram a assumir novas configurações, conteúdos, papéis e possibilidades no cenário social. Beck (1996, p. 225), nesta perspectiva, sentencia: "a família - o lugar e o refúgio de comunidade, da proximidade, da intimidade e do carinho precisamente na inospitalidade da modernidade - se converte em um monstro. No entanto, o que aqui se persegue é mostrar o alcance da contínua destruição, especificamente, da autodestruição". A esse fenômeno denomina "destradicionaliza- 
ção". Se, de um lado, ele liberta o indivíduo, trazendo novas possibilidades, para que ele configure novas relações dentro das antigas instituições sociais, de outro, gera insegurança, pois há um apego ao conteúdo e à segurança das antigas instituições. Nos relacionamentos, o outro será sempre ou uma condição de realização, com os respectivos ganhos, ou um risco em potencial, diante do qual eventualmente cabe se proteger.

[...] os confrontos entre os sexos surgidos com a destradicionalização da família emergem fundamentalmente na vida em comum, têm seu cenário de disputa na cozinha, na cama, e no quarto das crianças. Seu ruído de fundo e seu signo são as eternas discussões sobre a relação ou a muda confrontação no casamento; refugiando-se na solidão e refugiando-se dela; perdendo a confiança no outro, que de repente já não se pode compreender; sofrendo com a separação; deificando as crianças; lutando por uma porção de vida própria, que deve ser arrancada ao outro e, ainda assim, com ele dividida; percebendo a opressão no ridículo do dia a dia; a opressão que se é para si mesmo. Dê a isto o nome que se queira: 'entrincheiramento dos sexos', 'recuo à subjetividade', 'era do narcicismo'. Este é precisamente o modo pelo qual uma forma social - a trama estamental da sociedade industrial - implode no âmbito privado [...] (BECK, 2010, p. 163).

Se, na sociedade moderna, o postulado era a igualdade, e a luta de classes alicerçava uma melhor distribuição de riquezas, na sociedade de riscos, o postulado máximo centra-se na segurança, e a luta engendra-se, para que haja uma contenção social do risco.

Não há como negar que a modernização reflexiva traz riscos e inseguranças sociais, porque o indivíduo, acostumado às antigas estruturas sociais, passa, agora, a viver novas experiências, até então impensáveis dentro das estruturas sociais existentes. Seguindo Beck (1996) e Westphal (2010), na modernização reflexiva, o sujeito é atravessado por novas perspectivas sociais e culturais, além daquelas tra- 
dicionalmente conhecidas no início da modernidade. Com esse novo horizonte, emergem, todavia, novos riscos e inseguranças sociais, biográficas e culturais. Em decorrência da reconfiguração das bases de conduta, o indivíduo rearticula-se em seus enquadramentos de classe, grupo social, religião, vizinhança, gênero e arranjos familiares, ocorrendo, ainda, a respectiva fragilização dos nichos profissionais, do casamento, das situações e dos papéis sexuais, entre outras mudanças. A estrutura institucional e organizacional.

[...] se colapsa, mais concretamente, na decisão dos indivíduos. Estes são os vencedores e os perdedores da modernização reflexiva. Dito de outro modo: os efeitos colaterais supõem a liberação dos indivíduos do enjaulamento das instituições, neste caso, significam o renascimento de conceitos, tais como ação, subjetividade, conflito, saber, crítica e criatividade (BECK, 1996, p. 229).

A modernidade tardia, de certa forma, libertou os indivíduos das antigas formas de constituição social, como família, escola, igreja, entre outros aspectos. Nesse foco, cabe referir-se a um novo ímpeto do processo de individualização pelo qual cada um se torna a célula ou a unidade básica de reprodução vital do social. Nesse interim, se repõe a questão da individualização, como um fenômeno social renovado ou radicalizado. Por meio do processo que desemboca na individualização, alicerçado em uma específica racionalidade econômica e cultural, as relações interpessoais tendem ao isolamento do grupo social de pertencimento (BECK; BECK-GERNSHEIM, 2003), especialmente, na medida em que o nexo entre indivíduo e sociedade passa a ser temática, amplamente destacada desde os clássicos das ciências sociais.

Duas dimensões são indissociáveis nos critérios de análise no contexto social: a pertinência mútua entre modernização reflexiva e da individualização. Isso significa que os agentes de ação fundam suas formas de vida individual e coletiva e situam-se como a expressão de 
suas escolhas, e a referência ao outro sempre é como um agente com autonomia.

[...] a individualização é entendida, no processo de formação e constituição social, no qual o indivíduo é a referência central das ações no mundo social. Enquanto processo, é caracterizado por ambivalências e contradições: amplia e limita as possibilidades de ação dos indivíduos, sendo compreendido e experimentado como fardo e como chance concomitantemente (WESTPHAL, 2010, p. 420).

O paradigma de gestão dos riscos na contemporaneidade alça uma centralidade, quando atinge a intimidade, e o risco se evidencia nos encontros interpessoais da intimidade. $\mathrm{O}$ risco atingiu de tal forma a vida cotidiana e de diversas maneiras, inclusive em relação à sexualidade, que a preocupação com o cuidado pode atingir o prazer. Ainda que a modernidade tenha desconstituído antigas instituições, ela criou novas, mesmo que a partir de pressupostos críticos, nas quais os indivíduos foram novamente enquadrados:

[...] quanto aos indivíduos, porém - eles podem ser desculpados por ter deixado de notá-lo; passaram a ser confrontados por padrões e figurações que, ainda que "novas e aperfeiçoadas", eram tão duras e indomáveis como sempre. Na verdade, nenhum molde foi quebrado sem que fosse substituído por outro; as pessoas foram libertadas de suas velhas gaiolas apenas para ser admoestadas e censuradas caso não conseguissem se realocar, através de seus próprios esforços dedicados, contínuos e verdadeiramente infindáveis, nos nichos pré-fabricados da nova ordem: nas classes, as molduras que (tão intransigentemente como os estamentos já dissolvidos) encapsulavam a totalidade das condições e perspectivas de vida e determinavam o âmbito dos projetos e estratégias realistas de vida. A tarefa dos indivíduos livres era usar sua nova liberdade para encontrar o nicho apropriado e ali se acomodar e adaptar: seguindo fielmente as regras e modos de conduta identificados como corretos e apropriados para aquele lugar (BAUMAN, 2001, p. 13).

Porém, mesmo nessa fase, os indivíduos continuam a apegar-se aos antigos padrões comportamentais/institucionais ou a perce- 
bê-los com o olhar da modernidade, como ocorre com a judicialização das relações afetivas. Na sociedade em que a satisfação subjetiva coloca-se como prioridade, também os riscos do exercício das subjetividades e sexualidade assumirem uma posição central no ordenamento da vida cotidiana.

\section{A JUdicialização das RELAÇões INTERINDiVIDUAis E FAMILIARES}

O processo social chamado de "judicialização" possui diversas faces, que vão desde a constitucionalização de direitos até a ciência, pelos cidadãos, dos seus direitos. Há autores, entretanto, que entendem o termo em sentido mais largo, pois esse paradigma enseja inúmeras possibilidades e problemas no âmbito da pesquisa, entre elas, ativismo judicial, legitimidade, reconhecimento, efetivação dos direitos, subjetivação, adensamento democrático e "cidadanização" (XIMENES, 2012). A abordagem interdisciplinar do tema parece um requisito necessário, para examinar, pela mediação das ciências sociais, a judicialização das relações cotidianas. Beck (1996) se refere a este fenômeno constante das relações como as condições, nas quais o indivíduo se converte efetivamente em portador de direitos.

A complexidade e as contrariedades do fenômeno da judicialização, cuja tendência está focada nas relações interpessoais ou intersubjetivas, requerem o exercício da abordagem interdisciplinar, até para compreender o processo histórico e as expressões próprias em que se experimentam nova dinâmica de relações de poder.

Nessa perspectiva, é de se questionar, inclusive, se o período histórico da sociedade contemporânea tem relação com o fenômeno em destaque, principalmente, quando este fenômeno é observado não somente nas relações cotidianas como também, nas do âmbito familiar. O processo, enfocado no cotidiano, remete tanto à intensa normatização dos acontecimentos diários das relações humanas pelos 
mecanismos judiciais, quanto à decisão dos indivíduos de buscar a interlocução ou mediação, para obter ganhos na resolução de conflitos interindividuais.

A família moderna, diferentemente daquela da alta modernidade, era calcada nos valores de constância, segurança, estabilidade, proteção e amparo. Da mesma forma, os papéis sociais, atribuídos ao homem, à mulher e aos filhos, eram bem definidos. $\mathrm{O}$ pai, assim, assumia o papel de provedor, enquanto à mãe cumpria, tradicionalmente, o dever de cuidado familiar, e estas duas figuras fechavam-se em torno dos valores de sustento, proteção e cuidado com a prole.

Com efeito, há, nas democracias contemporâneas, uma ampliação do papel do Poder Judiciário na vida dos cidadãos, fenômeno este denominado "jurisdicionalização", pelo qual os cidadãos submetem a solução dos conflitos aos tribunais ou a outras instâncias adjudicatórias. O Conselho Nacional de Justiça - órgão criado pela Emenda Constitucional 45/2004 e em funcionamento desde junho de 2005, para exercer o controle administrativo e financeiro do Poder Judiciário apresenta relatórios ${ }^{4}$ anuais, concernentes aos números, associados à atuação do Poder Judiciário no Brasil. Em tais relatórios, pode-se observar o aumento efetivo da litigiosidade no país a partir do indicador chamado de "Litigiosidade e Carga de Trabalho", no qual é aferido o número de novos processos, ajuizados ao ano para cada 100.000 habitantes.

O fenômeno da judicialização é observado na grande recorrência de demandas sociais, dirigidas contra o Estado/Executivo, para sanar a omissão estatal na efetividade de direitos sociais. Contudo, a judicialização não tem sido observada apenas em demandas dos indivíduos contra o Estado ou grandes corporações financeiras, mas também, em relação às demandas interpessoais.

4 Diversos relatórios estão disponíveis em: http://www.cnj.jus.br/programas-de-a-a-z/eficiencia-modernizacao-e-transparencia/pj-justica-em-numeros/relatorios. 
As relações afetivas interpessoais giram cada vez mais em torno das exigências de perceptivas de realização individual, como fórmulas de realização subjetiva no amor. Tal realização, na sociedade da individualização, se desagrega ou se desdobra em suas próprias lógicas e se traduz em riscos e como questão exclusiva dos sujeitos, diretamente entrelaçados. Talvez, mais do que isto, tendo em vista a realização do imaginário, os amantes tendem a apostar em possíveis condutas bipolares: em legisladores de suas próprias condutas, dirão Beck e Beck-Gernsheim (2001), quando demandam autorregularem a sua convivência ou, em demandantes da judicialização, quando os conflitos destroem o diálogo e imaginam assegurar-se, em suas prerrogativas, com o recurso à instituição judiciária.

A guarda compartilhada dos filhos, requerida na justiça, é referente a uma participação afetiva e exatamente o inverso do clamor por punição dos denominados "genitores alienados" ou "ausentes afetivamente".

O que se percebe, nessas ações, é que, muitas vezes, os indivíduos, arraigados aos padrões sociais familiares, estabelecidos na modernidade, buscam o Poder Judiciário, para retomá-los, reforçá-los e/ou mantê-los ou desfazê-los. Nesse sentido, importa menos analisar os efeitos dos discursos e das práticas jurídicas sobre as subjetividades, e mais com as formas de os indivíduos se relacionarem, experimentarem e conceberem os efeitos de seus relacionamentos e de suas vidas cotidianas, as quais chegam aos tribunais.

Se, de um lado, se expandem as uniões interpessoais, sem formalização jurídica ou de convivência sob o mesmo teto, de outro, pode-se chamar atenção para a demanda por reconhecimento jurídico de novas formas de relações afetivas, como é o caso do casamento homoafetivo. Esse fenômeno pode ser entendido no sentido jurídico e na reinvenção de relacionamentos afetivos. 
Os desdobramentos, na realidade da individualização e da institucionalização ou judicialização, possuem capítulos contraditórios e, por vezes, complementares. $\mathrm{O}$ reconhecimento das relações de casal homossexual, como casamento, e similar à família, significa legitimidade para a diversidade, como assinalam Beck e Beck-Gernsheim (2001, p. 199): “Um tipo de família não marginalizará outro, senão simultaneamente um vasto leque de formas de convivência familiar e extrafamiliar".

Atualmente, o arquétipo da instituição familiar não mais se sustenta, e não se trata de assumir que o arquétipo familiar mudou, mas, sim, que não há mais arquétipo. Há um lugar de afeto, em torno do qual os sujeitos se organizam.

Nesse contexto, o Poder Judiciário se apresenta como uma tábua de salvação para a preservação das vivências familiares e experiências consolidadas na modernidade. A resolução, pela via judicial de conflitos relativos às relações intersubjetivas, pode ser uma ação tida como a jurisdicionalização das esferas sociais cotidianas ou pelo que Habermas chama de "colonização do mundo da vida" (HABERMAS, 1987a, 1987b). Rompe-se, desta forma, a lógica das ações comunicativas de consolidar um entendimento mútuo e racional, para aderir a metas que podem ter fins instrumentais ou estratégicos (XIMENES, 2012). O resultado do fenômeno de entendimento, por meio do consenso racional intersubjetivo, não está isento, consequentemente, dos riscos de dissensos e conflitos, tanto mais quando, devido aos fins almejados, o outro é compreendido ou transformado em meio/objeto para o atingimento de metas.

Veja-se, assim, o caso da mulher que, abandonada pelo namorado, socorreu-se do Judiciário, a fim de ser indenizada, porque, durante a constância da relação afetiva, foi vítima, segundo refere, de estelionato emocional, haja vista que o parceiro casou com outra mulher na constância da relação, e a autora, por diversas ocasiões, exerceu o 
papel de provedora do parceiro, contrariando a tradição moderna de um namoro.

\begin{abstract}
Segundo narra a sentença judicial, "alega a autora ter conhecido e iniciado uma "relação amorosa" com o réu em junho de 2010 que perdurou até maio de 2012, pouco tempo depois de ter descoberto que este havia se casado com outra mulher durante o curso da relação. Sustenta que já no final de 2010 o réu iniciou uma sequência de pedidos de empréstimos financeiros, empréstimos de carro, pedidos de créditos de celular e compras usando o cartão de crédito da requerente. Afirma que, ao todo, entre saques e transferências, entregou ao requerido o valor de $\mathrm{R} \$ 43.419,00$ (quarenta e três mil, quatrocentos e dezenove reais). [...] Ao final, sustentando ter suportado, além dos danos materiais, danos morais pela humilhação e situação vexatória que ficou perante amigos e familiares, pugna pela condenação do réu ao pagamento de $\mathrm{R} \$ 101.537,71$ (cento e um mil, quinhentos e trinta e sete reais e setenta e um centavos) a título de indenização por danos materiais, e R\$20.000,00 (vinte mil reais) a título de indenização por danos materiais. (DISTRITO FEDERAL, 2014).
\end{abstract}

Recentemente ${ }^{5}$, em São Paulo, um homem foi condenado a indenizar a ex-noiva, por cancelamento do casamento marcado. $\mathrm{O}$ rompimento da relação ocorreu cinco meses antes da data aprazada para o evento, e a condenação do noivo, contudo, circunscreve-se ao dever de indenizar os gastos, antecipados com vestido e preparo do casamento. O pedido da mulher à condenação do noivo, por dano moral (em razão do sofrimento suportado pelos fatos), foi negado à mulher, o que não afasta o fato de a situação ter despertado nela um sentimento de injustiça que poderia ser reparado pelo Judiciário.

Inúmeros, por fim, são os casos em que filhos, emocionalmente abandonados pelos pais ao longo da vida, ajuízam ação judicial, postulando a condenação daquele que promoveu ao abandono o pagamento de danos morais. Não se trata, portanto, de efetuar juízo

5 A decisão foi divulgada pela imprensa em 06/01/2015, contudo, dados específicos da decisão, como número do processo e nome das partes, não foram divulgados. (O PREÇO..., 2015). 
moral acerca da pretensão ao ressarcimento monetário, através da via judicial, daqueles que ajuízam ações dessa natureza. Trata-se, apenas, de perquirir até que ponto a sociedade de risco, em que pese contribuir para a formulação de novas configurações familiares, impacta na compreensão dos sujeitos acerca de si e de suas relações com os outros.

Fenômenos se entrecruzam na atualidade, e, entre eles, encontramos a tendência de reduzir questões da esfera político-social a intuições individuais, enquadrando as tensões no processo que denominamos “judicialização do cotidiano". Nessa lógica, de acordo com Oliveira e Brito (2013), conflitos familiares e relacionamentos afetivos informais passam por mudanças, geradas pelo modo como os sujeitos elaboram esses acontecimentos ou se desfazem deles. Os mais diversos relacionamentos são passíveis de serem judicializados, devido à percepção de perda, sendo iminente o risco de os sujeitos sofrerem cobranças dos outros, em função das suas relações cotidianas. Nas relações familiares, de cunho eminentemente íntimo, muitas vezes, a liberdade e as novas possibilidades de um indivíduo afetam as perspectivas da vida de outros, arraigados aos valores de segurança, estabilidade e previsibilidade.

\section{Considerações Finais}

A reflexão, a partir das ciências sociais, intenta compreender a confluência de aspetos da intimidade, destacados por meio de relações sociais. Sob o prisma analítico, Anthony Giddens aborda a dinamicidade e a fluidez das relações sociais na contemporaneidade. A esfera da intimidade expressa e configura campos conflituais. Em meio à individualização, os agentes reforçam e ajustam a possibilidade de urdir novas dimensões aos relacionamentos interpessoais e transformar os matizes da trama social. Na crise dos relacionamentos ou na busca de reconhecimento, os indivíduos acessam e mobilizam distintos em- 
preendimentos, entre os quais a judicialização, consolidando, assim, um processo que lhes permite a ressignificação ativa do universo das relações sociais.

Ao longo do texto, fomentamos uma análise reflexiva da judicialização, problematizando esse fenômeno, como um discurso, e as ações com as suas tensões e contradições. Esse fenômeno está situado histórica e socialmente, na medida em que compreende processos de um dado contexto das relações humanas, ao mesmo tempo em que se constitui como forma singela de regulação das condutas individuais e sociais.

A judicialização é, portanto, entendida como dispositivo de análise do funcionamento social e jurídico, tendo em vista a lógica de individualização, de publicização de relações afetivas e, eventualmente, de tendência à criminalização de condutas.

Nesse sentido, também compreendemos a judicialização como a produção ou a interferência direta dos demandantes nas subjetividades dos outros, as quais delimitam os modos de existência. Paradoxalmente, a possibilidade de reconhecer-se vítima de circunstâncias, engendradas em meio ao relacionamento afetivo, suscita um sujeito social, político e, por vezes, criador e suscetível às mudanças.

\section{REFERÊNCIAS}

BAUMAN, Zygmunt. Modernidade líquida. Rio de Janeiro: Jorge Zahar Editor, 2001.

BECK, Ulrich. Sociedade de risco: rumo a uma outra modernidade. São Paulo:

Editora 34, 2010.

BECK, Ulrich. Teoria de la sociedade del riesgo. In: BERIAIN, Josetxo (Coord.). Las consecuencias perversas de la modernidad: modernidad, contingencia y riesgo.

Barcelona: Anthropos, 1996. p. 201-222.

BECK, Ulrich; BECK-GERNSHEIM, Elisabeth. El normal caos del amor: las nuevas formas de la relación amorosa. Barcelona: Paidós, 2001. 
BECK, Ulrich; BECK-GERNSHEIM, Elisabeth. La individualización: el individualismo institucional y sus consecuencias sociales y políticas. Barcelona: Paidos, 2003.

DISTRITO FEDERAL. Tribunal de Justiça. Processo no 2013.01.1.046795-0 Cobrança: Autora: Suzana Oliveira del Bosco Tardim. Réu: Sérgio Antonio Pinheiro de Oliveira. Juiz: Luciano dos Santos Mendes. Julgado em : 8 set. 2014. Disponível em: <http://www.jusbrasil.com.br/diarios/76469082/djdf-11-09-2014-pg-690>. Acesso em: 13 fev. 2015.

GIDDENS, Anthony et al. Modernização reflexiva: política, tradição e estética na ordem social moderna. São Paulo: UNESP. 1997.

GUIVANT, Julia S. A trajetória das análises de risco: da periferia ao centro da teoria social. Revista Brasileira de Informações Bibliográficas, Rio de Janeiro, v. 46, p. 3-38, 1998.

HABERMAS, Jürgen. A nova intransparência: a crise do Estado de bem-estar social e o esgotamento das energias utópicas. Novos Estudos CEBRAP,São Paulo, n. 18, p. 103-114, 1987a.

HABERMAS, Jürgen. Teoria de la acción comunicativa. Madrid: Taurus, 1987b.

INSTITUTO HUMANITAS UNISINOS. Capitalismo do pós-guerra está no fim, diz Streeck. 2015. Disponível em: <http://www.ihu.unisinos.br/noticias/540406capitalismo-do-pos-guerra-esta-no-fim-diz-streeck>. Acesso em: 20 set. 2015.

O PREÇO da traição: ex-noivo pagará indenização por casamento cancelado. 2015. Disponível em: <http://www.migalhas.com.br/Quentes/17,MI213441,31047-Exnoiv o+pagara+indenizacao+por+casamento+cancelado>. Acesso em: 21 jan. 2015.

OLIVEIRA, Camilla F. B.; BRITO, Leila M. T. Judicialização da vida na contemporaneidade. Psicologia: Ciência e Profissão, Brasília, v. 33, p. 78-89, 2013.

WESTPHAL, Vera H. A individualização em Ulrich Beck: análise da sociedade contemporânea. Emancipação, Ponta Grossa, v. 10, n. 2, p. 419-433, 2010.

XIMENES, Julia Maurmann (Org.). Democracia e judicialização da política à luz dos direitos fundamentais. Brasília: IDP, 2012. 